\title{
Indian Journal of
}

\section{CRITICAL CARE MEDICINE}

Peer-reviewed, Official Publication of INDIAN SOCIETY OF CRITICAL CARE MEDICINE

Indian Journal of Critical Care

Medicine is indexed/listed with

Excerpta Medica/EMBASE, CAB

Abstracts, Global Health, CINAHL

Database, Cumulative Index to

Nursing and Allied Health Litera-

ture, MANTIS, Health \& Wellness

Research Center, Health Refer-

ence Center Academic, InfoTrac

One File, Expanded Academic

ASAP, electronic databases of

EBSCO, and Indian Science

Abstracts.

Indian Journal of Critical Care

Medicine is published quarterly

(in March, June, September and

December).

The information and opinions presented in Indian Journal of Critical

Care Medicine reflect the views of

the authors and not of the Society or the Editorial Board. Acceptance does not constitute endorsement by ISCCM.

All the rights are reserved. Apart from any fair dealing for the purposes of research or private study, or criticism or review, no part of the publication can be reproduced, stored, or transmitted, in any form or by any means, without the prior permission.

Indian Journal of Critical Care Medicine and/or its publisher cannot be held responsible for errors or for any consequences arising from the use of the information contained in this journal. The appearance of advertising or product information in the various sections in the journal does not constitute an endorsement or approval by the journal and/or its publisher of the quality or value of

the said product or of claims made for it by its manufacturer.

The Journal is printed on acid free paper.

EDITORIAL OFFICE

Dr. Sandhya Talekar

Chief Editor, IJCCM

Shree Medical Foundation, Prayag

Hospital, 1247, Deccan Gymkhana,

Pune 411004, India.

Tel: $91205532812 / 5532490$

Fax: 91205534448

E-mail: editor@ijccm.org

PUBLISHED BY

Medknow Publications

A-108/109, Kanara Business Center

Off Link Rd, Ghatkopar (E),

Mumbai - 400075, India.

Phone: 91-22-6649 1818 / 1816 ,

E-mail: publishing@medknow.com

\section{WEBSITES}

www.ijccm.org

www.bioline.org.br/cm

www.journalonweb.com/ijccm

\section{CHIEF EDITOR}

Dr. Sandhya Talekar

sandhya_talekar@yahoo.com

\section{EXECUTIVE EDITOR}

Dr. Shirish Prayag

shirishprayag@gmail.com

\section{ASSISTANT EDITORS}

\author{
Dr. R. K. Mani \\ rkmjs@vsnl.net \\ Dr. J. V. Divatia \\ jdivatia@vsnl.com
}

Dr. Farhad Kapadia

fnkapadia@gmail.com

\section{MEMBERS OF EDITORIAL BOARD}

Dr. S. S. Iyer (Pune)

s_iyer@vsnl.com

Dr. Atul Kulkarni (Mumbai)

kaivalyaak@yahoo.co.in
Dr. N. Ramakrishnan (Chennai)

icudoctor@gmail.com

Dr. Lalitha Pillai (Pune)

lalithapillai29@rediffmail.com

\section{PEDIATRIC SECTION}

Dr. K. Chugh

gangaram@giasdl01.vsnl.net.in

Dr. Sunit Singhi (Chandigarh)

drsinghi@glide.net.in
Dr. Pravin Khilnani (New Delhi) praveenk@nde.vsnl.net.in

Dr. Soonu Udani (Mumbai) drudani@hotmail.com

\section{NATIONAL ADVISORY BOARD}
Dr. M. B. Agarwal
Dr. H. S. Ballal
Dr. Dilip Karnad
Dr. Ram Rajagopalan
Dr. Manimala S. Rao
Dr. Subhash Todi
Dr. F. E. Udwadia
Dr. R. S. Wadia

\section{INTERNATIONAL ADVISORY BOARD}
Dr. David Baker (France)
Dr. Geoffrey Dobb (Australia)
Dr. Ken Hillman
Dr. Mitchell Levy (USA)
Dr. Michael Parr (Australia)
Dr. Ian Seppelt (Australia)

Dr. Laurent Brochard (France)

Dr. K. Guntupalli (USA)

Dr. Roop Kishen (UK)

Dr. Ramesh Nagappan (Australia)

Dr. Gilbert Park (UK)

Dr. J. L.Vincent (Belgium) 


\section{Indian Journal of \\ CRITICAL CARE MEDICINE}

\section{Official publication of Indian Society of Critical Care Medicine}

Oct-Dec 2007

\section{CONTENTS}

Volume 11, Issue 4

Editorials

It is not just the work - It is also the words

- Murali Ramaswam

T he ideal transfusion trigger in critically ill patients

- M. B. Agarwal

O riginal Articles

Review Article

Case Reports
An increase in weight worsens the respiratory state and leads to intensive care unit re-admission

- Yoshinori Matsuoka, Akinori Zaitsu

A prospective cohort study on anemia and blood transfusion in critically ill patients

- Naveen Manchal, S. Jayaram

Comparison of norepinephrine and dopamine in the management of septic shock using impedance cardiography

- Sharad K. Mathur, Rajiv Dhunna, Arpan Chakraborty

D etermination of intravascular volume status in critically ill patients using portable chest X-rays: M easurement of the vascular pedicle width

- Nawal Salahuddin, M. Aslam, Ishtiaq Chishti, Shehla Siddiqui

Role of physiotherapists in intensive care units of India: A multicenter survey

- Jithendra A. Kumar, Arun G. Maiya, Daphne Pereira

Postoperative pain and its management

- Sona Chaturvedi, Amit Chaturvedi 204

Rhabdomyolysis due to hair dye poisoning: An emerging threat

- Krishnaswamy Sampathkumar, Yesudas Santhakumari Sooraj, Rajappannair Prabha Ajeshkumar, Amol Ramesh Mahaldar, Ramakrishnan Muthiah

Severe hyperkalemia with normal electrocardiogram

- Sanjay Sharma, Harish Gupta, Meena Ghosh, Anantanarayan Padmanabhan 215 


\title{
Comparison of norepinephrine and dopamine in the management of septic shock using impedance cardiography
}

\author{
Sharad K. Mathur, Rajiv Dhunna*, Arpan Chakraborty**
}

Objective: Vasoconstrictors are one of the therapeutic modalities in the treatment of septic shock. In the present study, we have compared the effects of dopamine and norepinephrine in the treatment of septic shock with pre-defined end-points and continuous non-invasive cardiac output monitoring using impedance cardiography. Design: Randomized controlled trial. Settings: Sixteen-bedded mixed intensive care unit of a tertiary care teaching institution. Materials and Methods: The study included 50 consecutive patients presenting with septic shock and divided randomly into two groups with 25 patients in each group. Group I patients were treated with dopamine and those in Group II were treated with norepinephrine. They were optimized with fluid resuscitation upto CVP>10 $\mathrm{cm}$ of $\mathrm{H}_{2} \mathrm{O}$, packed red cells transfusion upto hematocrit $>30$, oxygenation and ventilation upto $\mathrm{PaO}_{2}>60 \mathrm{mmHg}$ before the inotropes were started. The goal of therapy was to achieve and maintain for six hours, all of the following: (1) SBP $>90 \mathrm{~mm} \mathrm{Hg}$, (2) SVRI $>1100$ dynes.s $/ \mathrm{cm}^{5} \mathrm{~m}^{2}$, (3) Cardiac Index $>4.0 \mathrm{~L} / \mathrm{min} / \mathrm{m}^{2}$, (4) IDO $\mathrm{IDO}_{2}>550 \mathrm{ml} / \mathrm{min} / \mathrm{m}_{2}$ and (5) $\mathrm{IVO}_{2}>150 \mathrm{ml} / \mathrm{min} / \mathrm{m}^{2}$. Measurements: The demographic data, baseline parameters and post-treatment parameters were statistically analyzed by using t-test. Results: The post-treatment parameters were statistically significant showing the superiority of norepinephrine over dopamine in optimization of hemodynamics and patient survival. Significant improvement in systolic blood pressure, heart rate, cardiac index, SVRI, IVO $\mathrm{IV}_{2}$ and urine output were found in norepinephrine group than the dopamine group. Dopamine showed a response in 10 out of 25 patients up to a maximum dose of 25 $\mathrm{mcg} / \mathrm{kg} / \mathrm{min}$ while with norepinephrine, 19 patients responded up to a maximum dose of $2.5 \mathrm{mcg} / \mathrm{kg} / \mathrm{min}$ The hemodynamic parameters were preserved in norepinephrine group with better preservation of organ perfusion and oxygen utilization with maintenance of splanchnic and renal blood flow as evidenced by significant increase in $\mathrm{O} 2$ uptake and urine flow. Conclusion: Norepinephrine was more useful in reversing the hemodynamic and metabolic abnormalities of septic shock compared to dopamine at the doses tested.
\end{abstract}

Key words: Dopamine, impedance cardiography, norepinephrine

From:

Department of Anesthesiology, Institute of Medical Sciences, Banaras Hindu University, Varanasi - 221 005, *Medical Intensive Care Unit, Fortis Hospital, Chandigarh; ${ }^{* *}$ Rabindranath Tagore International Institute of Cardiac Sciences, Kolkatta, India

\section{Correspondence:}

Arpan Chakraborty, Department of Anesthesiology, Rabindranath Tagore International Institute of Cardiac Sciences, Kolkatta, India.

E-mail: arpan_1977@sify.com

\section{Introduction}

Sepsis, inflammatory response to infection, directly or indirectly contributes to mortality in majority of the critically ill patients. An elevated cardiac index and a decreased systemic vascular resistance leading to hypotension and hypoperfusion of vital organs characterize the early stage of septic shock. The hypotensive state is 
often not amenable to fluid resuscitation alone and requires institution of vasoactive agents to counter the profound fall in systemic vascular resistance, which is an integral feature of septic shock. Vasoconstrictors are the main stay of treatment in reversing reversing the hemodynamic and metabolic abnormalities of hyperdynamic septic shock.

The more recent trend however focuses on monitoring the variables that have a direct influence on the outcome of septic shock. These include:

1. Systolic and mean arterial pressure (SBP and MAP)

2. Systemic vascular resistance index (SVRI)

3. Cardiac index $(\mathrm{Cl})$

4. Index of delivery of oxygen $\left(\mathrm{IDO}_{2}\right)$

5. Index of oxygen uptake $\left(\mathrm{IVO}_{2}\right)$

These variables may be monitored either invasively or non-invasively. Impedance cardiography, the non-invasive method of cardiac output monitoring, has been found to be a satisfactory substitute for invasive monitoring as it provides essentially similar information and is easier, quicker, cheaper and much safer to use..$^{[1-6]}$

Hence in the present study, the efficiency and dose requirement of two vasoconstrictors, dopamine and norepinephrine, were compared with predefined end points and continuous noninvasive hemodynamic monitoring.

\section{Materials and Methods}

The study was done in the intensive care unit of Institute of Medical Sciences, Banaras Hindu University, Varanasi and included 50 consecutive patients presenting with septic shock. The study was approved by the ethics committee. An informed consent was taken from the patients or their close relatives to get enrolled. Patients with two or more of the following criteria along with systolic blood pressure less than $90 \mathrm{~mm} \mathrm{Hg}$ were included - (1) body temperature greater than $38^{\circ} \mathrm{C}$ or less than $36^{\circ} \mathrm{C}$, (2) heart rate greater than $90 / \mathrm{min}$, (3) respiratory rate greater than 20/min and (4) WBC count more than 12000/ $\mathrm{cmm}$ or less than $4000 / \mathrm{cmm}$ or more than $10 \%$ bands. Internal jugular vein and radial artery of the patient was cannulated. The non-invasive cardiac output monitor, IQ System (Wantagh, Inc.) was connected to the patient by ECG lead system.

Crystalloids were used for resuscitation while at the same time packed red blood cells were administered to maintain a hematocrit more than 30 . The end point of resuscitation was defined as:

1. CVP more than $10 \mathrm{~cm} \mathrm{H}_{2} \mathrm{O}$

2. No further increase or a decrease in cardiac index with any further increase in fluid volume or appearance of clinical features of fluid overload.

The ventilatory status was assessed and was managed simultaneously with either invasive or non-invasive modes of ventilation, so as to maintain $\mathrm{PaO}_{2}$ more than $60 \mathrm{mmHg}$ and $\mathrm{PaCO}_{2}$ in a range of $35-40 \mathrm{mmHg}$. The arterial blood gases were measured at an interval of $30 \mathrm{~min}$ until ventilation and oxygenation status was optimized.

Patients enrolled in the study were randomly allocated to two groups according to vasoactive agent used [Table 1]. The outcome assessors were blinded to the drug the patient was receiving. However on their assessment and as per the set protocol of the study, the operator of the syringe pump was asked to change the doses of the drug. The person who manipulated the syringe pump knew what drug the patient was receiving and what were the set aliquots for that drug.

The goal of therapy was to achieve and maintain for six hours, all of the following:

1. SBP more than $90 \mathrm{~mm} \mathrm{Hg}$

2. SVRI more than 1100 dynes.s $/ \mathrm{cm}^{5} \mathrm{~m}^{2}$

3. Cardiac Index more than $4.0 \mathrm{~L} / \mathrm{min} / \mathrm{m}^{2}$

4. $\mathrm{IDO}_{2}$ more than $550 \mathrm{ml} / \mathrm{min} / \mathrm{m}^{2}$

5. $\mathrm{IVO}_{2}$ more than $150 \mathrm{ml} / \mathrm{min} / \mathrm{m}^{2}$

All the parameters were recorded every $15 \mathrm{~min}$. The

\section{Table 1: Study design}

Drug used

Dose range

Increments

Time interval

Termination of study

Group-I (25 patients)
Dopamine
$10-25 \mathrm{mcg} / \mathrm{kg} / \mathrm{min}$
$2.5 \mathrm{mcg} / \mathrm{kg} / \mathrm{min}$
$15 \mathrm{~min}$
Goal achieved or failure

Group-I (25 patients)

$0-25 \mathrm{mcg} / \mathrm{kg} / \mathrm{min}$

$15 \mathrm{~min}$
Group-II (25 patients)

Norepinephrine

$0.5-2.5 \mathrm{mcg} / \mathrm{kg} / \mathrm{min}$

$0.25 \mathrm{mcg} / \mathrm{kg} / \mathrm{min}$

$15 \mathrm{~min}$

Goal achieved or failure 
"responder" to the vasoactive agent used was a patient who achieved and maintained all the predefined goals of therapy for a period of six hours, in the specified dose range.

\section{Results}

The observations from the study were recorded and analyzed. Age, sex, weight and APACHE II scoring at the time of admission in ICU were compared by using student's t-test and the differences in the two groups were found non-significant [Table 2]. The baseline parameters were also found to be insignificant between the two groups [Table 3].

On comparison of the post-treatment parameters (at six hours in responders, or at maximum dose of vasoactive agent in non-responders) all, except $\mathrm{IVO}_{2}$, were found statistically significant $(P<0.05)$ by using $\mathrm{t}-$ test $(-4)$. Systemic vascular resistance index (SVRI) in group I patients increased from a mean of $672.88 \pm 32.16$ dynes.s $/ \mathrm{cm}^{5} \mathrm{~m}^{2}$ with only 10 of the 25 patients achieving and maintaining the preset goal of SVRI > 1,100 dynes. $\mathrm{s} / \mathrm{cm}^{5} \mathrm{~m}^{2}$. Group II patients showed a rise in SVRI from a mean baseline of $686.48 \pm 31.73$ dynes.s $/ \mathrm{cm}^{5} \mathrm{~m}^{2}$ to a mean post treatment value of $1123.60 \pm 185.72$ dynes. $\mathrm{s} / \mathrm{cm}^{5} \mathrm{~m}^{2}$.

\begin{tabular}{lccc}
\hline Table 2: Demographic data & & \\
\hline Parameter & $\begin{array}{c}\text { Dopamine } \\
\text { group } \\
\text { (Mean } \pm \text { SD) }\end{array}$ & $\begin{array}{c}\text { Norepnephrine } \\
\text { group } \\
\text { (Mean } \pm S D)\end{array}$ & $P$-value \\
Age (years) & $54.60 \pm 10.92$ & $52.76 \pm 10.41$ & $>0.05$ \\
Sex (M: F) & $17: 8$ & $15: 10$ & $>0.05$ \\
Weight (kg) & $58.32 \pm 9.43$ & $56.20 \pm 9.11$ & $>0.05$ \\
APACHE II & $24.56 \pm 2.90$ & $25.60 \pm 2.31$ & $>0.05$ \\
\hline
\end{tabular}

\begin{tabular}{|c|c|c|c|}
\hline \multicolumn{4}{|c|}{$\begin{array}{l}\text { Table 3: Comparison of baseline parameters between } \\
\text { dopamine and norepinephrine group }\end{array}$} \\
\hline Parameter & $\begin{array}{c}\text { Dopamine } \\
\text { group } \\
\text { (Mean } \pm S D)\end{array}$ & $\begin{array}{c}\text { Norepnephrine } \\
\text { group } \\
\text { (Mean } \pm S D \text { ) }\end{array}$ & $P$-value \\
\hline & & & \\
\hline St & & & 0.05 \\
\hline S & & & \\
\hline $\mathrm{Cl}\left(\mathrm{L} / \mathrm{min} / \mathrm{m}^{2}\right)$ & & & $>0.05$ \\
\hline $1 D O_{2}\left(\mathrm{ml} / \mathrm{min} / \mathrm{m}^{2}\right)$ & $731.71 \pm 74.53$ & $756.46 \pm 79.04$ & \\
\hline $\mathrm{IVO}_{2}^{2}\left(\mathrm{ml} / \mathrm{min} / \mathrm{m}^{2}\right)$ & $172.74 \pm 18.71$ & $179.54 \pm 19.23$ & $>0.05$ \\
\hline Urine output (ml/kg/hr) & $0.37 \pm 0.11$ & $0.34 \pm 0.28$ & $>0.05$ \\
\hline
\end{tabular}

Cardiac Index $(\mathrm{Cl})$ in group I patients demonstrated a significant upswing $\left(5.95 \pm 0.22 \mathrm{~L} / \mathrm{min} / \mathrm{m}^{2}\right)$ from the mean baseline $\left(5.23 \pm 0.53 \mathrm{~L} / \mathrm{min} / \mathrm{m}^{2}\right)$. Group II patients showed no significant rise in $\mathrm{Cl}$ from the baseline values.

The IDO $\mathrm{In}_{2}$ group I patients increased from a baseline mean of $731.71 \pm 74.54 \mathrm{ml} / \mathrm{min} / \mathrm{m}^{2}$ to a post treatment mean value of $827.35 \pm 31.65 \mathrm{ml} / \mathrm{min} / \mathrm{m}^{2}$. The mean IDO baseline value in group II patients showed no significant difference from the baseline mean in group I patients. The number of responders, effective dose of the vasopressor used and survivors are tabulated in Table 4.

\section{Discussion}

The early stage of septic shock is characterized by an elevated cardiac index and a decreased systemic vascular resistance, leading to hypotension and hypo perfusion of vital organs. One half of non-survivors of sepsis are estimated to die of refractory hypotension. ${ }^{[7]}$ Therefore, hemodynamic management of the septic patient to support blood pressure and thereby maintain perfusion to vital organs is an important aspect of care.

Hypotension is often not amenable to fluid (crystalloids or colloids) resuscitation alone and requires institution of vasoactive agents to counter the profound fall in systemic vascular resistance, which is an integral feature of septic shock. The controversy still rages regarding the ideal vasoactive agent and no universal agreement exists as to which of the agents available, should be used first.

Dopamine has been used widely as a first choice vasoactive agent in septic shock (Third European Consensus Conference in Intensive Care Medicine - Crit Care Med 1996). However, several studies have failed to demonstrate the restoration of adequate tissue perfusion, even with high doses of dopamine. These studies at the same time proved norepinephrine to be beneficial in restoring and maintaining arterial blood pressure and urine output in septic shock. ${ }^{[8-10]}$ Concerns regarding excessive vasoconstriction and impairment of tissue perfusion have persisted when using norepinephrine. Studies have shown that parameters of oxygen delivery and consumption are better markers

Table 4: Post-treatment response

\begin{tabular}{lcccc}
\hline Group & Responders & Non-responders & Effective dose range in responders (mcg/kg/min) & Survivors \\
Dopamine group & 10 & 15 & $15-20$ & 6 \\
Norepnephrine group & 19 & 6 & $1.5-2.5$ & 11 \\
\hline
\end{tabular}


of effective resuscitation. ${ }^{[11,12]}$ Our study therefore used parameters such $\mathrm{IDO}_{2}$ and $\mathrm{IVO}_{2}$, in addition to SBP and SVRI, to assess the comparative efficacy of dopamine and norepinephrine and also to allay concerns regarding their deleterious effects.

Before starting therapy the baseline heart rate of patients of both the groups was high. On treatment with dopamine in group I, heart rate rose significantly above the baseline. On the other hand those patients who were treated with norepinephrine (group II) showed a statistically significant decline in the heart rate compared to baseline. The post treatment increase in heart rate in group I patients was attributed to the chronotropic actions of dopamine, which in some patients led to significant tachyarrhythmia ( $\mathrm{HR}>140 / \mathrm{min})$. Tachycardia is primarily due to the $\beta$-adrenergic properties of dopamine that predominate in patients with sepsis. ${ }^{[13]}$ Moreover, the chronotropic sensitivity to $\beta$-adrenergic stimulation is increased in sepsis. ${ }^{[14]}$ This chronotropic effect of dopamine elevates myocardial oxygen demand, which may not be adequately met even by increased coronary blood flow. ${ }^{[15]}$ Patients on norepinephrine infusion on the other hand demonstrated a favorable profile, leading to a decrease in heart rate compared to the baseline. It can be attributed to an increase in systemic vascular resistance and thereby the MAP, leading to better organ perfusion and oxygen utilization.

Mean baseline SBP in group I patients showed no significant difference with the mean SBP in group II patients. However, post treatment the mean SBP in group II patients rose significantly [Table 5] while patients in group I showed a moderate rise. Only 10 of the 25 patients in group I showed a sustained rise of SBP $(>90 \mathrm{mmHg}$ for more than six hours) as opposed to 19 patients in group II. Thus, remaining 15 patients showed a relative dopamine resistance depicted by their inability to achieve and/or

\begin{tabular}{|c|c|c|c|}
\hline \multicolumn{4}{|c|}{$\begin{array}{l}\text { Table 5: Comparison of post-treatment parameters } \\
\text { between Group I and II }\end{array}$} \\
\hline Parameter & 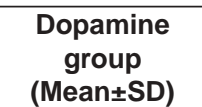 & $\begin{array}{c}\text { Norepnephrine } \\
\text { group } \\
\text { (Mean } \pm S D)\end{array}$ & $P$-value \\
\hline Heart rate (/min) & $141.64 \pm 8.67$ & $129.08 \pm 5.86$ & $<0.001$ \\
\hline & 36 & 112 & \\
\hline s.s $\left./ \mathrm{cm}^{5} \mathrm{~m}^{2}\right)$ & $922.60 \pm 264.78$ & $1123 \pm$ & $<0.05$ \\
\hline $\mathrm{Cl}\left(\mathrm{L} / \mathrm{min} / \mathrm{m}^{2}\right)$ & $5.95 \pm 0.22$ & $5.53 \pm 0.58$ & $<0.05$ \\
\hline $\mathrm{IDO}_{2}\left(\mathrm{ml} / \mathrm{min} / \mathrm{m}^{2}\right)$ & $827.35 \pm 31.65$ & $769.63 \pm 80.43$ & $<0.05$ \\
\hline $\mathrm{IVO}_{2}^{2}\left(\mathrm{ml} / \mathrm{min} / \mathrm{m}^{2}\right)$ & $210.62 \pm 11.31$ & $202.54 \pm 23.03$ & $>0.05$ \\
\hline Urine output (ml/kg/hr) & $0.81 \pm 0.75$ & $1.17 \pm 0.47$ & $<0.05$ \\
\hline
\end{tabular}

to maintain the preset SVRI and SBP, thereby leading to continued hypoperfusion of organs. Group II patients showed a significant rise in SVRI from the mean baseline value. This difference in the two groups can be attributed to more vasoconstrictive action of norepinephrine as compared to dopamine.

The positive inotropic and chronotropic effects of dopamine are responsible for rise in $\mathrm{Cl}$. However, mere rise in $\mathrm{Cl}$ is not sufficient per se, since studies have shown that survivors as well as non-survivors of septic shock may have a high $\mathrm{Cl}$, even within a few hours of death. ${ }^{[16]}$ Norepinephrine group showed no significant rise in $\mathrm{Cl}$ from the baseline mean despite the rise in SVRI and SBP. This compared favorably to prior studies, which have shown that a rise in SBP by a potent vasopressor at the expense of cardiac index leads to poor survival. ${ }^{[17]}$ Moreover the post-treatment $\mathrm{IDO}_{2}$ in group II patients $\left(769.63 \pm 80.43 \mathrm{ml} / \mathrm{min} / \mathrm{m}^{2}\right)$ showed no significant rise from its baseline. This showed that the rise in SVRI in group I I patients had no deleterious effect on $\mathrm{IDO}_{2}$.

Index of uptake of oxygen ( $\mathrm{IVO}_{2}$ ) in group I increased significantly $\left(210.62 \pm 11.23 \mathrm{ml} / \mathrm{min} / \mathrm{m}^{2}\right)$ over the mean baseline $\left(172.74 \pm 18.71 \mathrm{ml} / \mathrm{min} / \mathrm{m}^{2}\right)$. This was primarily attributed to increase in index of delivery of oxygen $\left(\mathrm{IDO}_{2}\right)$ and cardiac index $(\mathrm{Cl})$ rather than a fall in the venous oxygen content.

Norepinephrine administration demonstrated a significant rise in $\mathrm{IVO}_{2}$ over the baseline values but it was not statistically significant $(P>0.05)$ when compared to post-treatment $\mathrm{IVO}_{2}$ in dopamine group. Thus group II patients showed an increase in oxygen uptake by the tissues, which were dependent neither on increased $\mathrm{IDO}_{2}$ nor $\mathrm{Cl}$. This increase in uptake of oxygen in group II patients may be attributed to the correction of splanchnic ischemia. Prior studies have also demonstrated increase in splanchnic blood flow with norepinephrine infusion in sepsis. ${ }^{[18]}$ Under the influence of norepinephrine vascular reactivity is restored in sepsis towards the areas of greatest oxygen demand, thereby increasing uptake and optimizing oxygen extraction.

Group I patients showed an increase in urine output, while group II patients showed a significantly higher increase as compared to group I. Norepinephrine by virtue of its greater effect on the efferent rather than afferent 
arterioles increases the filtration fraction and helps to increase urine flow, with normalization of renal vascular resistance and also by the decrease in the ADH release.

Group I showed a response in 10 out of 25 patients. The non-responders in this group either failed to achieve and / or to maintain the predefined goals even with the maximum dopamine infusion dose $(25 \mathrm{mcg} / \mathrm{kg} / \mathrm{min})$. In group II 19 patients responded to norepinephrine infusion upto a dose of $2.5 \mathrm{mcg} / \mathrm{kg} / \mathrm{min}$. Thus norepinephrine was more useful in reversing the hemodynamic and metabolic abnormalities of septic sock compared to dopamine at the doses tested. The effective dose range in group I was 15 to $20 \mathrm{mcg} / \mathrm{kg} / \mathrm{min}$ with no patient responding below or above it whereas in group II the effective dose of norepinephrine was between $1.5 \mathrm{mcg} / \mathrm{kg} / \mathrm{min}$ to 2.5 $\mathrm{mcg} / \mathrm{kg} / \mathrm{min}$.

Six patients (24\%) in the dopamine group and 11 (44\%) patients in the norepinephrine group ultimately survived and were all 'responders'. The predominant cause of mortality in rest of the patients in both groups was multiple organ dysfunction.

The limitation of the study was that it only targeted the achievement of hemodynamic goals for a specific duration and thus the requirement of other vasoactive agents were not mentioned in both responders and non-responders. The inclusion criteria also did not consider the period of shock before starting therapy and the pre-existing organ dysfunction with which they presented to us. Also the requirement of other supportive measures like renal replacement therapy, duration of mechanical ventilation etc. were not taken into account in responders of both group.

\section{Conclusion}

The study shows that at the doses tested, norepinephrine is more effective and reliable than dopamine in reversing the hemodynamic and metabolic abnormalities of septic shock and patient survival. It leads to better supply and uptake of oxygen by the tissues. Moreover, norepinephrine shows no adverse effect on peripheral blood flow or on renal blood flow, as evidenced by normalization of urine output.

\section{References}

1. Shoemaker WC, Wo CC, Lu K, Chien LC, Rhee P, Bayard D, et al. Noninvasive hemodynamic monitoring for combat casualties. Mil Med 2006;171:813-20.

2. Shoemaker WC, Wo CC, Yu S, Farjam F, Thangathurai D. Invasive and noninvasive haemodynamic monitoring of acutely ill sepsis and septic shock patients in the emergency department. Eur $J$ Emerg Med 2000;7:169-75.

3. Shoemaker WC, Wo CC, Chan L, Ramicone E, Kamel ES, Velmahos GC, Belzberg H. Outcome prediction of emergency patients by noninvasive hemodynamic monitoring. Chest 2001;120:528-37.

4. Shoemaker WC, Bayard DS, Botnen A, Wo CC, Gandhi A, Chien LC, et al. Mathematical program for outcome prediction and therapeutic support for trauma beginning within $1 \mathrm{hr}$ of admission: A preliminary report. Crit Care Med. 2005;33:1647-8.

5. Shoemaker WC, Bishop MH. Noninvasive estimation of $\mathrm{CO}$ and circulatory dynamics in critically ill patients. Curr Opin Crit Care 1995;1:211-8.

6. Shoemaker WC, Wo CC, Bishop MH. Multi centered trial of a new thoracic electric bioimpedence devise for $\mathrm{CO}$ estimation. Crit Care Med 1994;22:190-7.

7. Marik PE. Gastric Intramucosal pH a better ptredictor of multiorgan dysfunction syndrome and death than oxygen-derived variables in patients with sepsis. Chest 1993;104:225-9.

8. Martin C, Viviand X, Leone M, Thirion X. Effect of norepinephrine on the outcome of septic shock. Crit Care Med 2000;28:2758-65.

9. Mills LC, Moyer JF, Handley CA. Effects of various sympathicomimetic drugs on renal hemodynamics in normotensive and hypotensive dogs. Am J Physiol 1960;198:1279-83.

10. Schaer GL, Fink MP, Parillo JE. Norepinephrine alone versus norepinephrine plus low dose dopamine: Enhanced renal blood flow with combination pressure therapy. Crit Care Med 1985;13:492-6.

11. Durham RM, Neunaber K, Mazuski JE, Shapiro MJ, Baue AE. The use of oxygen consumption and delivery as endpoints for resuscitation in critically ill patients. J Trauma 1996;41:32-40

12. Shoemaker WC, Appel PL, Kram HB. Oxygen transport measurements to evaluate tissue perfusion and titrate therapy. Crit Care Med 1991;19:672-88.

13. Rudis MI, Basha MA, Zarowitz BJ. Is it time to reposition vasopressors and inotropes in sepsis? Crit Care Med 1996;24:52537.

14. Smith LW, Winbery SL, Barker LA, McDonough KH. Cardiac function and chronotropic sensitivity to beta adrenergic stimulation is sepsis. Am J Physiol 1986;251:H405-12. 
15. Schreuder WO, Schneider AJ, Groenveld AB, Thijs LG. Effect of dopamine vs norepinephrine on hemodynamics in septic shock: Emphasis on right ventricular performance. Chest 1989;95:1282-8.

16. Abraham E, Bland RD, Cobo JC, Shoemaker WC. Sequential cardiorespiratory patterns associated with outcome in septic shock. Chest 1984;85:75-80.

17. Brown RS, Carrey JS, Mohr PA, Monson DO, Shoemaker WC. Comparative evaluation of sympathomimetic amines in clinical shock. Circulation 1966;34:260-71.

18. Takala J, Ruokonen E. Blood flow and adrenergic drugs in septic shock. In: Vincent JL, editor. Update in intensive care and emergency medicine. Berlin: Springer -Verlag; 1991. p. 144-62.

Source of Support: Nil, Conflict of Interest: None declared. 